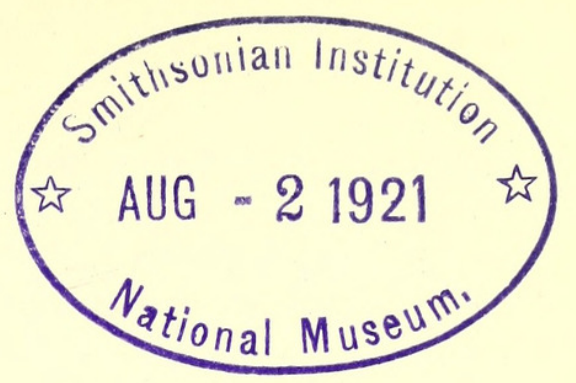

\title{
DETECTION OF INDUCED BETA-RAY EMISSION FROM SUBSTANCES EXPOSED TO RÖNTGEN-RAYS BY \\ A PHOTOGRAPHIC METHOD.*
}

\author{
By Lewis Simons, B.Sc.Lond., \\ Senior Lecturer in Physics in the University of Cape Town.
}

\section{(With Plate XIV.)}

Desiring to overcome the difficulty of having to take very many electroscope readings in the study of the speeds of $\beta$-particles emerging from atoms exposed to Röntgen-rays, I have attempted to record the particles photographically. The present paper deals with the preliminary results.

C. T. R. Wilson was the first to photograph the images of the tracks of these $\beta$-particles by means of his cloud experiments; but in the present work, as in the case of the photographic study of the emission of $\beta$-particles from radioactive substances, $\uparrow$ the particles themselves fall upon the photographic plate and produce an impression.

In some work that I hope to publish shortly an account is given of the manner in which the speeds of emergence of $\beta$-particles from ten different heavy atoms differ when exposed consecutively to two types of Röntgen-rays of wave-lengths $0.56 \times 10^{-8} \mathrm{~cm}$. and $0.38 \times 10^{-8} \mathrm{~cm}$. The ultimate object of this work is to determine these differences photographically. It was found that a copious $\beta$-radiation was emitted by a film of red-lead lightly dusted on to a slab of paraffin wax, and that when it was exposed to the Röntgen-rays of the shorter wave-length, the most rapid and normally directed particles moved over a maximum distance in atmospheric air of about $1.0 \mathrm{~cm}$. This maximum range is given by the two expressions $\frac{1}{2} m v^{2}=h v$ and $v^{4}=a d$, where $m$ is the mass of an electron $\left(8.8 \times 10^{-28} \mathrm{gm}\right.$. $)$, $h$ is Planck's constant $\left(6.56 \times 10^{-27} \mathrm{erg}\right.$. sec. $), v$ the frequency of the incident Röntgen-rays giving rise to a maximum speed of emergence $v$ of the particle from the atom, $d$ the range in normal air, and $a$ a constant for

* The expenses of this research are partly covered by a grant from the Union Government through the Research Committee of the Advisory Board of Industries and Science of the Union of South Africa.-L. S.

$\dagger$ e. $g$. see the reproduction of Hahn's photographs in 'Rutherford's Radioactive Substances and their Radiations' (1913), figs. $70 \mathrm{~A}$ and B. 
air* lying between $1 \times 10^{40}$ and $2 \times 10^{40}$. These numbers fix the dimensions of the apparatus needed, and fig. 1 represents the first arrangement adopted in order to secure a direct $\beta$-particle photograph. A "slit" of Röntgenrays $1.5 \mathrm{~mm}$. broad coming directly from the tungsten anticathode of a Coolidge tube fell upon the red-leaded surface of the wax slab A $\mathrm{B}$ placed at an angle of $6^{\circ}$ to the surface of the photographic plate $\mathrm{CD}$, the beam of Röntgen-rays being carefully "sighted" in a preliminary experiment so as to ensure that it did not touch the photographic plate, but ran parallel to its surface at a distance of about $0.2 \mathrm{~cm}$. from it. At $\mathrm{x}$ and $\mathrm{x}$ the red-lead was removed from the wax along two broad lines. This was done as a control, for paraffin wax emits no $\beta$-particles. The plates used were "Imperial Special Rapid," the exposure was for five minutes with 7 ampères in the primary of a Newton-Apps 10-in. coil, the tube backing up a parallel spark 3 in. in length between balls. The resulting photograph is shown in register in fig. 2 , and shows unmistakably that the impression has come from the red-lead film opposite. 'These photographs are positives, a darkening representing absence of photographic action. The line $\mathrm{y}$ is not clearly seen because it was much narrower than $\mathrm{x}$, the diffusion of the particles from surrounding regions rendering it invisible, and it probably fell on the edge of the incident beam.

In order to find how much of the effect is due to the diffusing $\beta$-particles or to the secondary Röntgen-rays from the red-lead, a cross of paraffin wax $0.005 \mathrm{~cm}$. in thickness and one of mica $0.00136 \mathrm{~cm}$. in thickness were stuck on to the photographic plate with a touch of glue (shown by the black spots in the middle of the crosses, fig. 3) in the region directly opposite to that part of the red-lead surface acted upon by the Röntgen-rays. The resulting photograph shows in a striking manner that of the two influences it is the $\beta$-radiation that produces the photographic impression, the photographic plate being effectively shielded by so small a mass of substance, far too small to be effective in stopping a Röntgen-ray beam properly so-called. The red-lead surface was about $0.35 \mathrm{~cm}$. above the wax cross and $0.5 \mathrm{~cm}$. above the mica one.

A preliminary experiment was now performed in order to determine the maximum range at which these particles could produce a photographic impression. Using the same arrangement as above, the angle between the slab and the photographic plate was doubled, and the whole system shifted laterally with respect to the incident beam of Röntgen-rays by intervals of $1 \mathrm{~mm}$., allowing a 3-minute exposure at each shift. In this manner practically the whole length of the red-leaded surface was exposed to the rays. In order to show up any effect on the photographic plate opposite, this was covered by a perforated strip of tissue paper $0.0034 \mathrm{~cm}$. thick, absorbing no Röntgen-rays falling on the plate but effectively stopping any $\beta$-particles. On the negative itself, fig. 4 , the strip is visible right to the

* Bohr gives $1.1 \times 10^{40}$, ' Phil. Mag.' (6), xxv, p. 28, 1913 . Whiddington $2 \cdot 1 \times 10^{40}$, 'Proc. Roy. Soc.' (A), lxxxvi (1912), p. 370. 
end of the plate, in which region the red-lead surface was at an approximate distance of $2 \mathrm{~cm}$. from it. Particles must therefore have traversed this distance in normal atmospheric air. Part of the impression must be due to $\beta$-radiation from the air itself, although fig. 2 shows that it cannot be very much. The limiting radiation from the Röntgen-ray tube will be tungsten " $\mathrm{K}$ " radiation of wave-length about $0.2 \times 10^{-8} \mathrm{~cm}$. Using this value and a rough average value, say $1.5 \times 10^{40}$, for Whiddington's absorption constant " $a$," the value of $d$, the maximum range in air of the $\beta$-particles should be about $3.3 \mathrm{~cm}$. As a matter of fact it is not easy to obtain the limiting rays from the tungsten anti-cathode, and I do not think they were present in the mixed beam falling upon the red-lead.

Figs. 5 and $5 \mathrm{~A}$ are perhaps of more general interest. In this and in several other similar experiments it was found that if the red-lead surface be replaced by a photographic plate the silver salts themselves give rise to a copious supply of electrons in the same manner as the lead, affecting another photographic plate at a considerable distance from the first. Fig. 5 shows the direct impression of the beam taken in the same manner as fig. 4 , and fig. 5 A shows the effect on the opposite plate upon which no direct Röntgen-rays fell. In fact, a similar effect would be given by any element of high atomic weight.

It is interesting to note that Sir W. H. Bragg * states that it is these electrons with which I have been dealing which cause the chemical action in the emulsion of a photographic plate when an ordinary X-ray photograph is taken in the usual manner. The number of particles and therefore the photographic effect can be increased by loading the film with a lead compound. Some experimenters have laid a thin sheet of lead on the film so that electrons generated in the considerable absorption of $\mathrm{X}$-rays by the lead may strike back on to the photographic plate. These particles will traverse only the thinnest films of solid, and we are bound to conclude from the study of these photographs when one examines the relative impressions due to $\beta$-particles and Röntgen-radiation from the same mass of substance, the latter being comparatively non-existent, that the latent image on a photographic plate, whether caused by ordinary light or X-rays, is inseparably associated with the ionisation of the molecule. By ionisation is meant the separation of one electron from the molecule. X-rays are ineffective on a photographic plate until the energy has been converted in the production of electrons ; these are the effective agents. When X-rays traverse a gas, the first act is to produce comparatively high-speed electrons which spend their energy in ionising local molecules. There is no reason to suppose that the process is different when X-rays are absorbed by a solid, such as, for example, the photographic film, except in that the range of action of the electrons is more limited.

* ‘Trans. Faraday Soc.,' xv, pt. 2, 1919 ; “ Symposium on Radiometallography,” p. 30. 


\section{$2 \mathrm{BHL}$ Biodiversity Heritage Library}

Simons, Lewis. 1921. "DETECTION OF INDUCED BETA-RAY EMISSION FROM SUBSTANCES EXPOSED TO RÖNTGEN-RAYS BY A PHOTOGRAPHIC METHOD." Transactions of the Royal Society of South Africa 9, 297-299. https://doi.org/10.1080/00359192109520220.

View This Item Online: https://www.biodiversitylibrary.org/item/181591

DOI: https://doi.org/10.1080/00359192109520220

Permalink: https://www.biodiversitylibrary.org/partpdf/175617

\section{Holding Institution}

Smithsonian Libraries

\section{Sponsored by}

Biodiversity Heritage Library

\section{Copyright \& Reuse}

Copyright Status: Not in copyright. The BHL knows of no copyright restrictions on this item.

This document was created from content at the Biodiversity Heritage Library, the world's largest open access digital library for biodiversity literature and archives. Visit BHL at https://www.biodiversitylibrary.org. 